\title{
Pengaruh Alokasi Belanja Operasi dan Belanja Modal pada Indeks Pembangunan Manusia
}

\section{Ida Ayu Tari Purnama Sasti ${ }^{1}$ Made Yenni Latrini ${ }^{2}$}

\author{
${ }^{1,2}$ Fakultas Ekonomi dan Bisnis Universitas Udayana (Unud), Bali, Indonesia \\ e-mail: tarisasti@gmail.com
}

\begin{abstract}
ABSTRAK
Penelitian ini bertujuan untuk mendapatkan bukti empiris mengenai pengaruh alokasi belanja operasi dan belanja modal pada indeks pembangunan manusia. Penelitian ini dilakukan di 9 Kabupaten/Kota Provinsi Bali. Populasi dalam penelitian ini adalah seluruh Laporan Realisasi Anggaran Pendapatan dan Belanja Daerah serta Indeks Pembangunan manusia seluruh Kabupaten/Kota Provinsi Bali tahun 2013-2017. Metode penentuan sampel yang digunakan adalah sampel jenuh, dengan jumlah sampel sebanyak 45 amatan. Teknik analisis data yang digunakan adalah analisis regresi linier berganda. Berdasarkan hasil penelitian menunjukkan bahwa belanja operasi berpengaruh pada indeks pembangunan manusia dan belanja modal tidak berpengaruh pada indeks pembangunan manusia.
\end{abstract}

Kata Kunci: Belanja operasi, belanja modal, indeks pembangunan manusia

\begin{abstract}
This study aims to obtain empirical evidence regarding the effect of operating expenditure and capital expenditure allocation on the human development index. This research was conducted in 9 regencies / cities in the province of Bali. The population in this study is the entire Report on Realization of Regional Revenues and Expenditures and the Human Development Index of all Regency / City of the Province of Bali in 2013-2017. The method of determining the sample used is a saturated sample, with a total sample of 45 observations. The data analysis technique used is multiple linear regression analysis. Based on the results of the study indicate that operating expenditure has an effect on the human development index and capital expenditure has no effect on the human development index.

Keywords: Operating expenditure, capital expenditure, human development index
\end{abstract}

\section{PENDAHULUAN}

Pembangunan manusia Indonesia seutuhnya dan pembangunan masyarakat Indonesia seluruhnya merupakan hakikat dari pembangunan nasional. Pernyataan tersebut menandakan bahwa manusia merupakan sentral dari suatu proses pembangunan (Adiputra dkk., 2015). Dalam mewujudkan suatu pembangunan nasional, maka salah satu langkah yang harus diperhatikan pemerintah adalah dengan meningkatkan kualitas pembangunan manusia (Connolly et al., 2014). 
Ida Ayu Tari Purnama Sasti dan Made Yenni Latrini. Pengaruh...

Kualitas pembangunan manusia diukur dengan indeks pembangunan manusia (IPM).

IPM diciptakan dan dipopulerkan oleh United Nations Development Programme (UNDP) sejak tahun 1990 dalam seri laporan tahunan yang diberi judul "Human Development Report" (UNDP, 1990: 1). IPM merupakan ukuran standar yang digunakan untuk mengatur pencapaian kualitas pembangunan manusia untuk hidup secara lebih baik yang dilihat dari aspek kesehatan, aspek pendidikan, maupun aspek ekonomi (Edeme, 2014). Konsep IPM menurut UNDP (2010) dan BPS (2017) adalah IPM dibentuk oleh tiga dimensi dasar yaitu umur panjang dan hidup sehat (a long and healthy life), pengetahuan (knowledge), dan standar hidup layak (decent standard of living). Variabel dalam IPM metode baru yaitu angka harapan hidup (AHH), rata-rata lama sekolah (RLS), angka harapan lama sekolah (HLS), dan pendapatan per kapita disesuaikan.

IPM di Indonesia terus mengalami peningkatan yang menandakan bahwa pembangunan manusia di Indonesia terus mengalami kemajuan (Sari et al., 2017). Walaupun mengalami peningkatan dari tahun 2015-2017 secara berturut-turut yaitu tahun 2015 sebesar 68,90, tahun 2016 sebesar 70,18, dan tahun 2017 sebesar 70,81, namun dalam laporan pembangunan manusia oleh UNDP tahun 2015, capaian IPM di Indonesia menempati urutan ke lima diantara negara-negara regional Association of Southeast Asian Nations (ASEAN) yaitu Singapura, Brunei Darussalam, Malaysia dan Thailand. Dari data tersebut dapat dilihat bahwa Indonesia masih perlu banyak perbaikan dalam peningkatan kualitas pembangunan manusia. 
Pemerintah telah mengeluarkan Undang-Undang Nomor 32 Tahun 2004 yang telah diubah menjadi Undang-Undang Nomor 23 Tahun 2014 tentang Pemerintahan Daerah (Mardiasmo, 2018: 24). Undang-undang ini memberikan hak, wewenang, dan kewajiban daerah otonom untuk mengatur dan mengurus sendiri urusan pemerintahan dan kepentingan masyarakat setempat dalam sistem NKRI. Kebijakan ini disebut dengan otonomi daerah. Otonomi daerah memberikan kewenangan bagi pemerintah daerah untuk menghasilkan pendapatan daerahnya secara mandiri sesuai dengan potensi dan aspirasi masyarakat setempat untuk mengembangkan wilayahnya serta melakukan alokasi untuk prioritas pembangunan di daerahnya guna meningkatkan kesejahteraan, sehingga upaya perbaikan kualitas pembangunan manusia di Indonesia tidak dapat dilepaskan dari usaha simultan untuk meningkatkan IPM kabupaten atau kota di Indonesia. Salah satunya adalah kabupaten/kota di Provinsi Bali.

Kabupaten/kota di Provinsi Bali sebagian besar telah mencapai angka capaian IPM yang baik, namun masih terdapat kabupaten/kota yang belum mencapai IPM dengan status tinggi dan masih berada di bawah capaian IPM Provinsi Bali sehingga hal tersebut menimbulkan kesenjangan. IPM kabupaten/kota di Provinsi Bali tahun 2013-2017 disajikan pada Tabel 1 berikut. 
Tabel 1.

IPM Kabupaten/Kota di Provinsi Bali Tahun 2013-2017

\begin{tabular}{lcccccc}
\hline \multicolumn{1}{c}{ Kabupaten / Kota } & & & Tahun & & & Status IPM \\
& $\mathbf{2 0 1 3}$ & $\mathbf{2 0 1 4}$ & $\mathbf{2 0 1 5}$ & $\mathbf{2 0 1 6}$ & $\mathbf{2 0 1 7}$ & Tahun 2017 \\
\hline Kabupaten Jembrana & 68,39 & 68,67 & 69,66 & 70,38 & 70,72 & Tinggi \\
Kabupaten Tabanan & 72,31 & 72,68 & 73,54 & 74,19 & 74,86 & Tinggi \\
Kabupaten Badung & 77,63 & 77,98 & 78,86 & 79,80 & 80,54 & Sangat Tinggi \\
Kabupaten Gianyar & 74,00 & 74,29 & 75,03 & 75,70 & 76,09 & Tinggi \\
Kabupaten Klungkung & 68,08 & 68,30 & 68,98 & 69,31 & 70,13 & Tinggi \\
Kabupaten Bangli & 65,47 & 65,75 & 66,24 & 67,03 & 68,24 & Sedang \\
Kabupaten Karangasem & 63,70 & 64,01 & 64,68 & 65,23 & 65,57 & Sedang \\
Kabupaten Buleleng & 68,83 & 69,19 & 70,03 & 70,65 & 71,11 & Tinggi \\
Kota Denpasar & 81,32 & 81,65 & 82,24 & 82,58 & 83,01 & Sangat Tinggi \\
Provinsi Bali & 72,09 & 72,48 & 73,27 & 73,65 & 74,30 & Tinggi \\
\hline Sumber: Badan Pusat Statistik, 2018 & & & & &
\end{tabular}

Kesenjangan angka capaian IPM kabupaten/kota di Provinsi Bali menunjukkan adanya indikasi kebijakan otonomi daerah khususnya dalam pengalokasian Anggaran Pendapatan dan Belanja Daerah (APBD) belum dapat dimanfaatkan secara optimal untuk kesejahteraan masyarakat. Priambodo dan Noor (2015) menjelaskan bahwa APBD digunakan pemerintah untuk membiayai pembangunan sesuai komponen-komponen terkait pembangunan manusia. Pemerintah daerah diharapkan mengalokasikan belanja daerah melalui pembangunan yang sesuai dengan sektor-sektor pendukung untuk meningkatkan IPM, seperti pada bidang pendidikan, bidang kesehatan, dan bidang infrastruktur (Ehimare et al., 2014).

Belanja dikelompokkan berdasarkan klasifikasi ekonomi, yaitu belanja operasi, belanja modal, dan belanja tak terduga (PSAP 02 PP 71 Tahun 2010). Belanja operasi adalah pengeluaran anggaran untuk kegiatan sehari-hari pemerintah daerah yang memberi manfaat jangka pendek. Belanja operasi terdiri dari belanja pegawai, belanja barang, belanja bunga, belanja subsidi, belanja 
hibah, dan belanja bantuan sosial. Belanja modal adalah pengeluaran yang dilakukan dalam rangka pembelian/pengadaan atau pembangunan aset tetap berwujud yang mempunyai nilai manfaat lebih dari 12 (dua belas) bulan untuk digunakan dalam kegiatan pemerintahan (Permendagri Nomor 13 Tahun 2006).

Bila dilihat pada Laporan Realisasi APBD Kabupaten/Kota Provinsi Bali tahun 2013-2017, realisasi belanja operasi dan belanja modal tertinggi adalah Kabupaten Badung pada tahun 2017 yaitu secara berturut-turut sebesar Rp 3.209.358.800.394,26 dan Rp 1.241.111.664.922,39. Sedangkan realisasi belanja operasi dan belanja modal yang terendah adalah Kabupaten Bangli pada tahun 2013 yaitu secara berturut-turut sebesar $\mathrm{Rp} \quad 520.472 .320 .770$ dan $\mathrm{Rp}$ 62.762.963.319. Jika diselaraskan dengan capaian IPM Kabupaten/Kota Provinsi Bali pada Tabel 1, menunjukkan suatu fenomena bahwa walaupun Kabupaten Badung memiliki realisasi belanja operasi dan belanja modal tertinggi namun angka capaian IPM tertinggi tidak diraih oleh Kabupaten Badung, serta Kabupaten Bangli dengan realisasi belanja operasi dan belanja modal paling rendah namun angka capaian IPM terendah tidak pada Kabupaten Bangli.

Menurut Pahlevi (2017), jumlah realisasi belanja daerah tidak dapat menjelaskan seberapa efektif dan efisien pengeluaran yang dihabiskan yang artinya realisasi belanja daerah yang tinggi tidak selalu berarti bahwa pengeluaran tersebut efektif. Hal ini menunjukkan bahwa tinggi rendahnya jumlah realisasi belanja operasi dan belanja modal tidak menentukan capaian IPM. Penentuan capaian IPM dapat dilihat melalui apakah belanja operasi dan belanja modal sudah dialokasikan untuk kebutuhan masyarakat yang sesuai dengan komponen dalam 
Ida Ayu Tari Purnama Sasti dan Made Yenni Latrini. Pengaruh...

penghitungan IPM sehingga bertujuan untuk meningkatkan kesejahteraan masyarakat.

Belanja operasi dalam peningkatan IPM dapat dilihat pada bidang pendidikan dan bidang kesehatan. Berdasarkan Undang-Undang Nomor 15 Tahun 2013, minimal persentase yang dicapai untuk anggaran pendidikan dari total belanja daerah sebesar 20 persen. Sedangkan, persentase anggaran kesehatan minimal 10 persen dari APBD (UU Nomor 36 Tahun 2009). Belanja operasi yang dialokasikan tepat sasaran untuk peningkatan AHH, RLS, HLS, dan pendapatan per kapita tentu akan berpengaruh pada IPM. Hasil tersebut sejalan dengan penelitian Sasana (2012) serta Dewi dan Supadmi (2016) bahwa belanja operasi berpengaruh pada IPM. Namun, hasil yang berbeda ditemukan oleh penelitian Deswantoro dkk. (2017) bahwa belanja pegawai dan belanja hibah yang termasuk dalam belanja operasi tidak berpengaruh pada IPM. Zebua dan Adib (2014) juga menjelaskan bahwa belanja hibah dan belanja bantuan sosial yang termasuk dalam belanja operasi tidak berpengaruh pada IPM.

Belanja modal dialokasikan oleh pemerintah daerah untuk pengadaan aset daerah sebagai investasi (Hukom, 2015). Pemerintah pusat menghimbau pemerintah daerah agar persentase belanja modal sebesar 30 persen dari total belanja daerah (Perpres Nomor 5 Tahun 2010), namun proporsi belanja modal di Kabupaten/Kota Provinsi Bali sebagian besar masih dibawah 30 persen kecuali Kabupaten Badung, sehingga belanja modal dianggap belum memberikan dampak yang maksimal untuk meningkatkan kesejahteraan masyarakat. Proporsi realisasi 
belanja modal terhadap total belanja di Kabupaten/Kota Provinsi Bali Tahun 2013-2017 disajikan pada Tabel 2 berikut.

Tabel 2.

Proporsi Realisasi Belanja Modal terhadap Total Belanja di Kabupaten/Kota Provinsi Bali Tahun 2013-2017 (dalam persentase)

\begin{tabular}{lcccccc}
\hline \multicolumn{1}{c}{ Kabupaten / Kota } & & & & & & \\
& $\mathbf{2 0 1 3}$ & $\mathbf{2 0 1 4}$ & $\mathbf{2 0 1 5}$ & $\mathbf{2 0 1 6}$ & $\mathbf{2 0 1 7}$ & Rata-Rata \\
\hline Kabupaten Jembrana & 21,17 & 21,86 & 22,80 & 32,22 & 26,66 & 24,94 \\
Kabupaten Tabanan & 11,40 & 10,94 & 8,02 & 15,55 & 18,01 & 12,78 \\
Kabupaten Badung & 33,20 & 34,70 & 33,56 & 35,24 & 27,81 & 32,90 \\
Kabupaten Gianyar & 16,49 & 16,73 & 16,43 & 19,95 & 24,37 & 18,79 \\
Kabupaten Klungkung & 10,02 & 13,25 & 14,69 & 22,36 & 18,51 & 15,77 \\
Kabupaten Bangli & 10,74 & 10,21 & 13,75 & 26,01 & 18,84 & 15,91 \\
Kabupaten Karangasem & 17,76 & 16,32 & 14,72 & 14,89 & 17,81 & 16,30 \\
Kabupaten Buleleng & 13,87 & 12,52 & 13,35 & 17,52 & 15,96 & 14,64 \\
Kota Denpasar & 17,19 & 15,12 & 12,16 & 15,30 & 14,41 & 14,83 \\
\hline Sumbr & & & & & &
\end{tabular}

Sumber: Biro Keuangan Provinsi Bali, 2018

Belanja modal yang dialokasikan untuk fasilitas pendidikan, kesehatan dan sarana prasarana lainnya seperti infrastruktur daerah dan fasilitas umum yang memadai tentu akan meningkatkan pelayanan sektor publik secara berkelanjutan sehingga berpengaruh pada IPM (Ndakularak dkk., 2015). Umiyati dkk. (2017) dalam penelitiannya menjelaskan bahwa peningkatan alokasi belanja modal akan diikuti dengan peningkatan IPM. Hasil ini sejalan dengan penelitian Ishak (2016) serta Sari dan Supadmi (2016) bahwa belanja modal berpengaruh pada IPM. Namun, hasil yang berbeda ditemukan oleh Kresnandra (2016) serta Pramartha dan Dwirandra (2018) bahwa belanja modal tidak berpengaruh pada IPM.

Berdasarkan fenomena yang telah diungkapkan dan juga hasil penelitian terdahulu yang menunjukkan inkonsistensi, maka peneliti tertarik untuk meneliti kembali pengaruh alokasi belanja operasi dan belanja modal pada indeks pembangunan manusia kabupaten/kota di Provinsi Bali. Perbedaan dengan penelitian sebelumnya bahwa data yang akan diteliti adalah laporan realisasi 
Ida Ayu Tari Purnama Sasti dan Made Yenni Latrini. Pengaruh...

APBD tahun 2013 hingga 2017 dari kabupaten/kota di Provinsi Bali. Selain itu, IPM pada penelitian ini menggunakan data poin IPM dengan penghitungan metode baru yang diterapkan oleh UNDP sejak tahun 2010 .

Teori keagenan (agency theory) menjelaskan hubungan antara pihak agen dengan prinsipal (Jensen dan Meckling, 1976). Jubery et al. (2017) menjelaskan bahwa pemerintah daerah provinsi dan kabupaten/kota sering mempraktekkan agency theory dalam menyusun rancangan APBD. Pada sektor publik, yang berperan sebagai prinsipal adalah masyarakat yang diproksikan oleh DPRD dan agennya adalah pemerintah daerah. Keterkaitan teori agensi dengan penelitian ini adalah hubungan antara masyarakat (prinsipal) dengan pemerintah daerah (agen). Peningkatan pendapatan asli daerah telah diperoleh dari masyarakat (prinsipal) melalui membayar pajak, retribusi, dan lainnya. Timbal balik kepada masyarakat sudah seharusnya diberikan oleh pemerintah daerah (agen) melalui pengalokasian belanja daerah dalam upaya memenuhi kebutuhan publik sehingga kesejahteraan masyarakat dapat tercapai dan dapat meningkatkan IPM (Prasetyo dan Zuhdi, 2013).

Slavinskaite (2016) menyatakan bahwa secara teoritis desentralisasi fiskal merupakan devolusi tanggung jawab fiskal dan kekuasaan dari pemerintah pusat ke pemerintah daerah yang dapat meningkatkan atau mengurangi pertumbuhan ekonomi. Terdapat dua perspektif teori dalam desentralisasi fiskal yaitu teori perspektif tradisional dan teori perspektif baru. Teori perspektif tradisional menjelaskan mengenai keuntungan alokatif dari desentralisasi (Hayek, 1945). Teori perspektif baru menjelaskan mengenai pentingnya revenue dan expenditure 
assignment antar level pemerintahan (Musgrave, 1959; Oates, 1972). Desentralisasi fiskal memiliki fungsi utama yaitu untuk peningkatan efisiensi sektor publik (Jumadi et al., 2013). Desentralisasi fiskal memberikan manfaat untuk tata kelola sektor publik, meliputi pertumbuhan, akuntabilitas, dan responsivitas para pemerintah terhadap tuntutan lokal dan kebutuhan masyarakat (Fiddin et al., 2018). Gogoi (2017) dan Soejoto et al. (2015) mengemukakan bahwa desentralisasi fiskal menghimbau pemerintah daerah agar mampu memberikan fasilitas pelayanan publik yang optimal untuk seluruh masyarakat setempat. Untuk mencapai salah satu tujuan utama dari desentralisasi fiskal, yakni meningkatkan kualitas pelayanan umum dan kesejahteraan masyarakat maka pemerintah daerah dituntut untuk mengelola keuangan daerahnya dengan baik dan mengalokasikan belanja daerah untuk memberikan fasilitas pelayanan publik yang lebih baik untuk masyarakat lokal sehingga nantinya akan meningkatkan IPM dari suatu daerah (Yusuf dan Gunanto, 2014).

Belanja operasi yang telah dilaksanakan oleh pemerintah kabupaten/kota dalam urusan kesehatan yaitu belanja operasi jenis belanja pegawai dalam penyediaan tenaga kesehatan yang memadai dan berkompeten dan belanja operasi jenis belanja sosial dalam membiayai program jaminan kesehatan masyarakat yang miskin atau tidak mampu di kabupaten/kota. Penyediaan tenaga kesehatan yang berkompeten dan memadai di puskesmas maupun RSUD diharapkan dapat melakukan proses persalinan dengan baik, sehingga dapat mencegah kematian ibu dan kematian bayi. Dalam pembiayaan program jaminan kesehatan untuk masyarakat yang tidak mampu diterapkan dengan memberikan bantuan iuran 
Ida Ayu Tari Purnama Sasti dan Made Yenni Latrini. Pengaruh...

BPJS kesehatan dari pemerintah daerah. Dengan bantuan iuran BPJS tersebut diharapkan semakin banyak masyarakat yang miskin atau tidak mampu mendapatkan layanan kesehatan dari pemeriksaan, rawat inap, dan obat dengan gratis khususnya saat pemeriksaan kelahiran dan proses persalinan. Hal tersebut menyebabkan penurunan AKI dan AKB, kemudian akan meningkatkan angka harapan hidup dan IPM (Pradana, 2018).

Belanja operasi yang telah dilaksanakan oleh pemerintah dalam urusan pendidikan adalah menyediakan tenaga pendidik yang memadai dan berkualitas serta pendanaan program wajib belajar. Dengan tersedianya tenaga pendidik yang memadai dan berkualitas serta biaya pendidikan yang gratis, diharapkan partisipasi masyarakat untuk menjalani pendidikan formal akan meningkat (Zahari dan Sudirman, 2017). Hal tersebut akan meningkatkan harapan lama sekolah, indeks pendidikan, dan IPM.

Penelitian yang dilakukan Dewi dan Supadmi (2016) serta Pradana (2018) menjelaskan bahwa belanja operasi berpengaruh pada IPM. Sejalan dengan penelitian Zebua dan Adib (2014) yaitu belanja barang dan jasa yang merupakan bagian dari belanja operasi berpengaruh signifikan terhadap IPM. Sasana (2012) mengemukakan bahwa manusia akan mengalami peningkatan taraf hidup jika belanja operasi dialokasikan tepat sasaran oleh pemerintah daerah dalam menunjang kinerja untuk pelayanan masyarakat. Berdasarkan uraian tersebut maka dapat disusun hipotesis sebagai berikut.

$\mathrm{H}_{1}$ : Belanja operasi berpengaruh pada indeks pembangunan manusia di Kabupaten/Kota Provinsi Bali 
Berdasarkan UU 32 tahun 2004 yang diubah menjadi UU 23 tahun 2014, urusan pendidikan ialah urusan wajib pemerintah kabupaten/kota. Belanja modal dalam urusan pendidikan meliputi pembangunan gedung sekolah negeri. Pemerintah kabupaten/kota mengalokasikan belanja modal untuk membangun gedung sekolah agar terjadi peningkatan daya tampung sekolah. Meningkatnya jumlah siswa tentu menandakan bahwa terjadinya peningkatan partisipasi masyarakat untuk bersekolah. Hal tersebut akan meningkatkan harapan lama sekolah, indeks pendidikan, dan IPM.

Syam et al. (2018) menjelaskan bahwa kualitas dan kuantitas produktivitas daerah serta pendapatan masyarakat dapat meningkat jika belanja modal dialokasikan secara tepat untuk pembenahan infrastruktur daerah serta fasilitas umum yang memadai. Penelitian yang dilakukan Azzahra dkk. (2016), Sari dan Supadmi (2016), serta Umiyati dkk. (2017) mendapatkan hasil bahwa belanja modal berpengaruh pada IPM. Berdasarkan uraian tersebut maka dapat disusun hipotesis sebagai berikut.

$\mathrm{H}_{2}$ : Belanja modal berpengaruh pada indeks pembangunan manusia di Kabupaten/Kota Provinsi Bali

\section{METODE PENELITIAN}

Pendekatan kuantitatif yang berbentuk asosiatif digunakan dalam penelitian ini, yang menjelaskan permasalahan yang akan diteliti yaitu mengenai pengaruh variabel belanja operasi dan belanja modal pada IPM. Lokasi penelitian ini yaitu Biro Keuangan Provinsi Bali dan Badan Pusat Statistik (BPS) Provinsi Bali. Ruang lingkup dalam penelitian ini yaitu di Kabupaten/Kota Provinsi Bali. Obyek 
Ida Ayu Tari Purnama Sasti dan Made Yenni Latrini. Pengaruh...

dalam penelitian ini adalah indeks pembangunan manusia Kabupaten/Kota di Provinsi Bali tahun 2013-2017 yang dipengaruhi oleh beberapa faktor, yaitu belanja operasi dan belanja modal.

Variabel-variabel yang digunakan meliputi variabel dependen yaitu IPM (Y) dan variabel independen yaitu belanja operasi $\left(\mathrm{X}_{1}\right)$ dan belanja modal $\left(\mathrm{X}_{2}\right)$. Pengukuran variabel IPM sejalan dengan yang digunakan oleh Dewi dan Supadmi (2016) serta Pradana (2018) yaitu sebagai berikut.

$\mathrm{IPM}=$ Poin IPM dari BPS

Belanja operasi dalam penelitian ini diukur dengan menggunakan nilai logaritma natural yang sejalan dengan yang digunakan oleh Dewi dan Supadmi (2016) serta Pradana (2018) yaitu sebagai berikut.

Belanja operasi $=\ln ($ realisasi anggaran belanja operasi pada APBD).

Belanja modal dalam penelitian ini diukur dengan menggunakan nilai logaritma natural yang sejalan dengan yang digunakan oleh Dewi dan Supadmi (2016) serta Pradana (2018) yaitu sebagai berikut.

Belanja modal $=\ln ($ realisasi anggaran belanja modal pada APBD)

Populasi dalam penelitian ini adalah seluruh laporan realisasi APBD Kabupaten/Kota di Provinsi Bali tahun 2013-2017 dan IPM Kabupaten/Kota di Provinsi Bali tahun 2013-2017. Penentuan sampel dalam penelitian ini dilakukan dengan menggunakan metode sampling jenuh yaitu teknik penentuan sampel bila semua anggota populasi digunakan sebagai sampel (Sugiyono, 2017: 120), dalam penelitian ini meliputi laporan realisasi APBD kabupaten/kota di Provinsi Bali dan IPM Kabupaten/Kota Provinsi Bali tahun 2013-2017 meliputi 8 kabupaten 
dan 1 kota dengan waktu penelitian yaitu 5 tahun dari tahun 2013-2017. Jadi, jumlah sampel dalam penelitian ini adalah sebanyak 45 amatan. Sumber data dalam penelitian ini adalah data sekunder, yaitu berupa dokumen-dokumen yang terdapat pada Biro Keuangan Provinsi Bali dan situs resmi kementrian keuangan di www.djpk.kemenkeu.go.id berupa laporan realisasi APBD tahun 2013-2017 dan IPM tahun 2013-2017 yang dikeluarkan oleh BPS Provinsi Bali.

Teknik analisis data pada penelitian ini meliputi analisis statistik deskriptif, uji asumsi klasik yang terdiri dari uji normalitas, uji multikolinearitas, uji autokorelasi dan uji heteroskedastisitas, analisis regresi linier berganda, uji koefisien determinasi $\left(\mathrm{R}^{2}\right.$ ), uji kelayakan model (uji F), serta uji hipotesis ( uji t). Persamaan regresi linier berganda dalam penelitian ini yaitu sebagai berikut.

$\mathrm{Y}=\mathrm{a}+\beta_{1} \mathrm{X}_{1}+\beta_{2} \mathrm{X}_{2}+e$

Keterangan :

\begin{tabular}{|c|c|}
\hline Y & $=$ Indeks pembangunan manusia \\
\hline $\mathrm{a}$ & $=$ Konstanta \\
\hline$\beta_{1}, \beta_{2}$ & $=$ Koefisien regresi \\
\hline $\mathrm{X}_{1}$ & $=$ Belanja operasi \\
\hline $\mathrm{X}_{2}$ & $=$ Belanja modal \\
\hline & $=$ Standard error \\
\hline
\end{tabular}

\section{HASIL DAN PEMBAHASAN}

Daerah atau wilayah penelitian yang digunakan dalam penelitian ini adalah Kabupaten/Kota di Provinsi Bali meliputi Kabupaten Jembrana, Kabupaten Tabanan, Kabupaten Badung, Kabupaten Gianyar, Kabupaten Klungkung, Kabupaten Bangli, Kabupaten Karangasem, Kabupaten Buleleng, dan Kota Denpasar. 
Ida Ayu Tari Purnama Sasti dan Made Yenni Latrini. Pengaruh...

Statistik deskriptif dalam penelitian ini disajikan untuk memberikan informasi mengenai karakteristik variabel-variabel penelitian berupa nilai minimum, nilai maksimum, nilai rata-rata (mean), dan deviasi standar.

Tabel 3.

Hasil Analisis Statistik Deskriptif

\begin{tabular}{lrrrrr}
\hline & N & \multicolumn{1}{c}{ Minimum } & \multicolumn{1}{c}{ Maximum } & \multicolumn{1}{c}{ Mean } & \multicolumn{1}{c}{ Std. Deviation } \\
\hline IPM & 45 & 63,70 & 83,01 & 72,1478 & 5,56873 \\
$\begin{array}{l}\text { Belanja } \\
\text { Operasi }\end{array}$ & 45 & $520.472 .320 .770,00$ & $3.209 .358 .800 .394,26$ & $1.134 .851 .389 .404,90$ & $505.755 .247 .134,34$ \\
$\begin{array}{l}\text { Belanja } \\
\text { Modal }\end{array}$ & 45 & $62.762 .963 .319,00$ & $1.241 .111 .664 .922,39$ & $292.191 .133 .871,98$ & $275.252 .577 .962,20$ \\
$\begin{array}{l}\text { Valid N } \\
\text { (listwise) }\end{array}$ & 45 & & & & \\
\hline
\end{tabular}

Nilai rata-rata IPM sebesar 72,15 persen dan deviasi standar sebesar 5,57. Nilai tertinggi sebesar 83,01 persen dimiliki oleh Kota Denpasar pada tahun 2017. Nilai terendah sebesar 63,70 persen diraih oleh Kabupaten Karangasem tahun 2013.

Nilai rata-rata belanja operasi sebesar Rp. 1.134.851.389.404,90 dan deviasi standar sebesar 505.755.247.134,34. Nilai tertinggi sebesar Rp. 3.209.358.800.394.26 dimiliki oleh Kabupaten Badung pada tahun 2017. Nilai terendah sebesar 520.472.320.770,00 dimiliki oleh Kabupaten Bangli tahun 2013.

Nilai rata-rata belanja modal sebesar Rp. 292.191.133.871,98 dan deviasi standar sebesar 275.252.577.962,20. Nilai tertinggi sebesar Rp. 1.241.111.664.922,39 dimiliki oleh Kabupaten Badung pada tahun 2017. Nilai terendah sebesar Rp. 62.762.963.319.00 yang dimiliki oleh Kabupaten Bangli tahun 2013 . 
Setelah melakukan pengujian statistik deskriptif, dilakukan uji asumsi klasik yang terdiri dari uji normalitas, uji autokorelasi, uji mulitkolinearitas, dan uji heteroskedastisitas (Ghozali, 2018: 159).

Tabel 4.

Hasil Uji Normalitas

\begin{tabular}{lc}
\hline & Unstandardized Residual \\
\hline $\mathrm{N}$ & 45 \\
Kolmogorov-Smirnov Z & 1,074 \\
Asymp. Sig. (2-tailed) & 0,199 \\
\hline Sumber: Data diolat, 2018
\end{tabular}

Sumber: Data diolah, 2018

Hasil uji normalitas menunjukkan nilai Asymp. Sig. (2-tailed) sebesar 0,199 (> 0,05). Hal ini menunjukkan bahwa pada model regresi yang digunakan dalam penelitian telah berdistribusi normal.

Tabel 5.

Hasil Uji Autokorelasi

\begin{tabular}{cc}
\hline Model & Durbin-Watson \\
\hline 1 & 1,701
\end{tabular}

Sumber: Data diolah, 2018

Hasil uji autokorelasi menunjukkan nilai DW yang dihasilkan sebesar 1,701. Pada Tabel Durbin Watson dengan jumlah $\mathrm{n}=45$ dan $\mathrm{k}=2$ diperoleh nilai $\mathrm{d}_{\mathrm{L}}=1,4298$ dan $\mathrm{d}_{\mathrm{U}}=1,6148$ sehingga nilai $4-\mathrm{d}_{\mathrm{U}}=2,5702$, maka $\mathrm{d}_{\mathrm{U}}<\mathrm{dw}<4-\mathrm{d}_{\mathrm{U}}$ yaitu $(1,6148<1,701<2,5702)$. Hal tersebut menunjukkan data dalam penelitian ini tidak mengandung autokorelasi.

Tabel 6.

Hasil Uji Multikolinearitas

\begin{tabular}{lcc}
\hline & \multicolumn{2}{c}{ Collinearity Statistics } \\
Model & Tolerance & VIF \\
\hline Ln Belanja Operasi & 0,404 & 2,478 \\
Ln Belanja Modal & 0,404 & 2,478 \\
\hline Sumber: Data diolah, 2018 & \multicolumn{2}{c}{}
\end{tabular}

Sumber: Data diolah, 2018

Hasil uji multikolinearitas menunjukkan variabel belanja operasi dan belanja modal memiliki nilai tolerance diatas 0,1 dan nilai VIF dibawah 10 . Hal 
Ida Ayu Tari Purnama Sasti dan Made Yenni Latrini. Pengaruh...

ini menunjukkan bahwa data dalam penelitian ini tidak terjadi gejala multikolinearitas.

Tabel 7.

Hasil Uji Heteroskedastisitas

\begin{tabular}{|c|c|}
\hline Model & Sig. \\
\hline $\begin{array}{ll}1 & \text { (Constant })\end{array}$ & 0,026 \\
\hline Ln Belanja Operasi & 0,090 \\
\hline Ln Belanja Modal & 0,748 \\
\hline
\end{tabular}

Hasil uji heteroskedastisitas menunjukkan nilai signifikansi untuk masingmasing variabel independen terhadap nilai logaritma kuadrat residual lebih besar dari 0,05 . Hal ini menunjukkan bahwa model regresi yang digunakan dalam penelitian ini bebas dari gejala heteroskedastisitas.

Analisis regresi linier berganda digunakan untuk mengetahui besarnya pengaruh belanja operasi $\left(\mathrm{X}_{1}\right)$, belanja modal $\left(\mathrm{X}_{2}\right)$, dan indeks pembangunan manusia (Y).

Tabel 8.

Hasil Analisis Regresi Linier Berganda

\begin{tabular}{|c|c|c|c|c|c|}
\hline \multirow[b]{2}{*}{ Model } & \multicolumn{2}{|c|}{$\begin{array}{c}\text { Unstandardized } \\
\text { Coefficients }\end{array}$} & \multirow{2}{*}{$\begin{array}{c}\begin{array}{c}\text { Standardized } \\
\text { Coefficients }\end{array} \\
\text { Beta } \\
\end{array}$} & \multirow[b]{2}{*}{$\mathbf{T}$} & \multirow[b]{2}{*}{ Sig. } \\
\hline & B & Std. Error & & & \\
\hline $1 \quad$ (Constant) & $-173,991$ & 44,056 & & $-3,949$ & 0,000 \\
\hline Ln Belanja Operasi & 7,757 & 2,388 & 0,571 & 3,249 & 0,002 \\
\hline Ln Belanja Modal & 1,204 & 1,441 & 0,147 & 0,836 & 0,408 \\
\hline
\end{tabular}

Berdasarkan hasil analisis regresi linier berganda, maka persamaan regresi yang digunakan dalam penelitian ini adalah sebagai berikut.

$$
\mathrm{Y}=-173,991+7,757 \mathrm{X}_{1}+1,204 \mathrm{X}_{2}+e
$$

Nilai konstanta sebesar -173,991 menunjukkan bahwa apabila alokasi belanja operasi dan belanja modal sama dengan nol, maka IPM akan menurun sebesar 173,991 satuan. Nilai koefisien regresi belanja operasi sebesar 7,757 
menunjukkan bahwa apabila alokasi belanja operasi naik sebesar satu persen, maka IPM akan meningkat sebesar 7,757 satuan dengan asumsi variabel lainnya sama dengan nol. Nilai koefisien regresi belanja modal sebesar 1,204 menunjukkan bahwa apabila alokasi belanja modal naik sebesar satu persen, maka IPM akan meningkat sebesar 1,204 satuan dengan asumsi variabel lainnya sama dengan nol.

Tabel 9.

Hasil Uji Koefisien Determinasi

\begin{tabular}{lcccc}
\hline Model & R & R Square & Adjusted R Square & $\begin{array}{c}\text { Std. Error of the } \\
\text { Estimate }\end{array}$ \\
\hline 1 & $0,691^{\text {a }}$ & 0,477 & 0,452 & 4,12260 \\
\hline Sumber $:$ Data & & &
\end{tabular}

Sumber : Data diolah, 2018

Hasil uji koefisien determinasi menunjukkan nilai Adjusted $R^{2}$ sebesar 0,452. Hal ini memiliki arti bahwa 45,2 persen perubahan IPM dipengaruhi atau dijelaskan oleh belanja operasi dan belanja modal, sedangkan sisanya sebesar 54,8 persen dijelaskan oleh faktor-faktor lain yang tidak dimasukkan ke dalam model.

Tabel 10.

Hasil Uji Kelayakan Model (Uji F)

\begin{tabular}{llcc}
\hline Model & & F & Sig. \\
\hline 1 & $\begin{array}{l}\text { Regression } \\
\text { Residual } \\
\text { Total }\end{array}$ & 19,141 & $0,000^{\mathrm{a}}$ \\
& & \\
\hline Sumber $:$ Data diolah, 2018 & &
\end{tabular}

Hasil uji kelayakan model menunjukkan nilai signifikansi F sebesar 0,000 lebih kecil dari nilai $\alpha=0,05$ yang berarti bahwa model penelitian ini layak digunakan. Hal ini menunjukkan bahwa variabel belanja operasi dan belanja modal berpengaruh secara bersama-sama terhadap variabel dependennya yaitu indeks pembangunan manusia. 
Tabel 11.

Hasil Uji Hipotesis (Uji t)

\begin{tabular}{|c|c|c|c|c|c|}
\hline \multicolumn{6}{|c|}{ Unstandardized Coefficients } \\
\hline & & B & Std. Error & $\mathbf{T}$ & Sig. \\
\hline \multirow[t]{3}{*}{1} & (Constant) & $-173,991$ & 44,056 & $-3,949$ & 0,000 \\
\hline & Ln Belanja Operasi & 7,757 & 2,388 & 3,249 & 0,002 \\
\hline & Ln Belanja Modal & 1,204 & 1,441 & 0,836 & 0,408 \\
\hline
\end{tabular}

Berdasarkan hasil uji hipotesis menunjukkan koefisien regresi variabel belanja operasi sebesar 7,757 dengan tingkat signifikansi sebesar 0,002 lebih kecil dari taraf signifikansi $(\alpha)$ sebesar 0,05 . Hal ini menunjukkan bahwa belanja operasi berpengaruh pada IPM, sehingga hipotesis pertama $\left(\mathrm{H}_{1}\right)$ diterima. Hasil ini sejalan dengan penelitian Dewi dan Supadmi (2016) serta Pradana (2018) bahwa belanja operasi berpengaruh pada indeks pembangunan manusia. Hasil penelitian tersebut menjelaskan manusia akan mengalami peningkatan taraf hidup jika belanja operasi dialokasikan dengan tepat sasaran dalam meningkatkan kinerja untuk pelayanan kepada masyarakat (Sasana, 2012) .

Berpengaruhnya belanja operasi pada IPM Kabupaten/Kota di Provinsi Bali dikarenakan proporsi belanja operasi yang tinggi dengan rata-rata pada tahun 2013-2017 yaitu lebih dari 65 persen telah dialokasikan dengan cukup efektif untuk peningkatan sektor-sektor pendukung dalam pencapaian IPM yaitu urusan kesehatan, pendidikan, dan ekonomi. Belanja operasi jenis belanja pegawai yang dialokasikan dalam penyediaan tenaga kesehatan yang berkompeten dan memadai akan menyebabkan penurunan AKI dan AKB yang kemudian akan meningkatkan angka harapan hidup yang merupakan komponen dari IPM. Belanja operasi jenis belanja pegawai yang dialokasikan dalam penyediaan tenaga pendidik yang 
memadai dan kompeten tentu akan menyebabkan peningkatan angka partisipasi sekolah yang kemudian akan meningkatkan harapan lama sekolah, dan IPM.

Belanja operasi jenis belanja bantuan sosial yang dialokasikan untuk membiayai pelaksanaan program wajib belajar seperti pada Pemerintah Kabupaten Jembrana yang memiliki program wajib belajar 12 tahun tentu akan meningkatkan partisipasi warga untuk menempuh pendidikan sehingga meningkatkan harapan lama sekolah yang merupakan komponen dari IPM (Pemkab, 2016). Belanja operasi jenis belanja bantuan sosial yang dialokasikan untuk jaminan kesehatan masyarakat miskin atau tidak mampu oleh pemerintah kabupaten/kota diberikan melalui bantuan iuran BPJS kesehatan atau Kartu Krama Badung Sehat (KBS) yang dimiliki oleh Pemerintah Kabupaten Badung (Bappeda, 2017). Peningkatan belanja operasi jenis belanja bantuan sosial yang dialokasikan untuk jaminan kesehatan masyarakat miskin atau tidak mampu tentu semakin banyak masyarakat yang akan mendapatkan layanan kesehatan dari pemeriksaan, rawat inap, dan obat dengan gratis khususnya saat pemeriksaan kelahiran dan proses persalinan. Hal tersebut akan menurunkan angka kematian ibu dan anak yang kemudian akan meningkatkan angka harapan hidup yang merupakan komponen dari IPM. Penelitian Mittal (2016) juga mendapatkan hasil bahwa belanja operasi jenis belanja bantuan sosial berpengaruh pada IPM.

Belanja operasi jenis belanja hibah yang dialokasikan secara tepat sasaran untuk pemberdayaan masyarakat seperti pengembangan UMKM melalui pembinaan dan kemudahan akses pendanaan bagi UMKM tentu akan menambah ragam produk yang dapat dihasilkan oleh para pelaku UMKM sehingga 
Ida Ayu Tari Purnama Sasti dan Made Yenni Latrini. Pengaruh...

meningkatkan pendapatan masyarakat dan IPM. Belanja operasi jenis belanja barang yang dialokasikan untuk membiayai operasional program dan kegiatan pemerintah daerah tentu akan meningkatkan pendapatan masyarakat sehingga berpengaruh pada IPM. Hal ini dikarenakan produsen akan menghasilkan barang sesuai dengan kebutuhan sehingga akan meningkatan pendapatannya (Deswantoro dkk., 2017).

Hasil penelitian ini mendukung teori keagenan (agency theory). Pemerintah daerah sebagai agen sudah memberikan timbal balik sesuai dengan kebutuhan masyarakat (prinsipal) melalui pengalokasian belanja operasi untuk pelayanan kepada masyarakat sehingga kesejahteraan dapat tercapai dan meningkatkan IPM. Hasil penelitian ini juga mendukung teori federalisme fiskal (fiscal federalism). Keuntungan dari desentralisasi fiskal adalah pengalokasian belanja daerah yang efisien karena pemerintah daerah berlokasi lebih dekat dengan masyarakatnya sehingga pemerintah daerah mampu mengalokasikan belanja operasi untuk memberikan fasilitas pelayanan yang lebih baik untuk masyarakat setempat sehingga mampu meningkatkan IPM.

Hasil pengujian pengaruh belanja modal $\left(\mathrm{X}_{2}\right)$ pada IPM $(\mathrm{Y})$ menunjukkan koefisien regresi variabel belanja modal sebesar 1,204 dengan tingkat signifikansi sebesar 0,408 lebih besar dari taraf signifikansi $(\alpha)$ sebesar 0,05. Hal ini menunjukkan bahwa belanja modal tidak berpengaruh pada IPM, sehingga hipotesis kedua $\left(\mathrm{H}_{2}\right)$ ditolak. Hasil penelitian ini tidak berhasil membuktikan penelitian yang dilakukan oleh Azzahra dkk. (2016) dan Umiyati dkk. (2017). Namun, penelitian ini sejalan dengan penelitian Kresnandra (2016), Pramartha 
dan Dwirandra (2018), serta Prihastuti (2018) yang menyatakan bahwa belanja modal tidak berpengaruh pada indeks pembangunan manusia. Penghitungan IPM yang berbeda pada indeks pendidikan menyebabkan perbedaan hasil penelitian ini dengan hasil penelitian terdahulu. Indikator IPM metode lama pada indeks pendidikan menggunakan angka melek huruf (AMH). Sedangkan, indikator IPM metode baru menggunakan harapan lama sekolah (HLS).

Belanja modal yang terkait dengan IPM Kabupaten/Kota yaitu pada urusan pendidikan melalui pengalokasian belanja modal seperti pembangunan gedung sekolah. Pembangunan gedung sekolah baru biasanya tidak diikuti dengan peningkatan jumlah siswa baru pada tahun bersangkutan dikarenakan pembangunan gedung sekolah rampung untuk waktu yang cukup lama. Hal tersebut mengakibatkan belanja modal yang telah dialokasikan untuk membangun sekolah pada tahun anggaran saat ini, manfaatnya akan dapat dinikmati pada tahun anggaran berikutnya saat penerimaan siswa baru. Peningkatan belanja modal yang dialokasikan untuk pembangunan gedung sekolah tidak secara serta merta meningkatkan partisipasi masyarakat untuk bersekolah pada tahun anggaran belanja modal dikeluarkan. Hal tersebut kemungkinan mengakibatkan belanja modal tidak berpengaruh pada IPM. Belanja modal yang dialokasikan untuk pelayanan publik tahun berkenaan yang juga manfaatnya baru dirasakan beberapa tahun ke depan oleh masyarakat secara tidak merta meningkatkan IPM pada tahun saat anggaran belanja modal dikeluarkan.

Tidak berpengaruhnya belanja modal pada IPM juga disebabkan oleh proporsi belanja modal yang cukup rendah dengan rata-rata selama tahun 2013- 
Ida Ayu Tari Purnama Sasti dan Made Yenni Latrini. Pengaruh...

2017 di setiap Kabupaten/Kota di Provinsi Bali kurang dari 30 persen, kecuali pada Kabupaten Jembrana pada tahun 2016 dan Kabupaten Badung. Rendahnya proporsi realisasi belanja modal tersebut tidak mampu memberikan peningkatan kesejahteraan yang optimal bagi masyarakat, terutama terkait dengan komponen dalam IPM yaitu indeks kesehatan, indeks pendidikan, dan pendapatan perkapita disesuaikan.

Sesuai dengan teori keagenan (agency theory), pemerintah daerah sebagai agen sudah memberikan timbal balik kepada masyarakat (prinsipal) melalui pengalokasian belanja modal untuk pelayanan publik, namun proporsi belanja modal yang dialokasikan masih rendah sehingga belum memberikan hasil yang optimal untuk kesejahteraan masyarakat sehingga tidak berpengaruh pada IPM.

Implikasi teoritis pada penelitian menghasilkan simpulan mengenai pengaruh alokasi belanja operasi dan belanja modal pada indeks pembangunan manusia di Kabupaten/Kota Provinsi Bali. Terdapat bukti empiris yang menunjukkan belanja operasi berpengaruh pada IPM dan belanja modal tidak berpengaruh pada IPM. Implikasi praktis pada penelitian ini adalah sebagai bahan pertimbangan dalam pengalokasian belanja daerah agar saat perencanaan APBD dilakukan sebijak mungkin untuk memenuhi kebutuhan masyarakat.

\section{SIMPULAN}

Simpulan berdasarkan hasil penelitian yang telah dilakukan adalah belanja operasi berpengaruh pada IPM di Kabupaten/Kota Provinsi Bali dan belanja modal tidak berpengaruh pada IPM di Kabupaten/Kota Provinsi Bali. 
Saran yang diberikan pada penelitian ini yaitu bagi pemerintah daerah diharapkan dapat mengalokasikan belanja operasi dan belanja modal dengan sebijak mungkin pada saat perencanaan APBD untuk peningkatan kesejahteraan masyarakat khususnya di sektor-sektor pendukung dalam capaian IPM. Selain itu, Pemerintah Daerah Kabupaten/Kota di Provinsi Bali diharapkan mencapai persentase belanja modal sebesar 30 (tiga puluh) persen sesuai dengan Peraturan Presiden Republik Indonesia Nomor 5 Tahun 2010 tentang Rencana Pembangunan Jangka Menengah Nasional. Bagi peneliti selanjutnya sebaiknya menggunakan variabel belanja menurut urusan kabupaten/kota meliputi belanja urusan kesehatan, belanja urusan pendidikan, dan belanja infrastruktur, serta sebaiknya memperluas rentang waktu penelitian untuk melihat perkembangan belanja daerah dan IPM di Kabupaten/Kota Provinsi Bali agar diperoleh perbedaan hasil saat menggunakan indikator IPM metode lama dan indikator IPM metode baru.

\section{REFERENSI}

Adiputra, I. M. P, Dwiyantari, N. K. D., \& Darmada D. K. (2017). Pengaruh PAD, Dana Perimbangan dan SiLPA terhadap Kualitas Pembangunan Manusia dengan Alokasi Belanja Modal sebagai Variabel Intervening (Studi pada Pemerintah Kabupaten/Kota di Bali). JIMAT (Jurnal Ilmiah Mahasiswa Akuntansi S1), 5(3), 1-34.

Azzahra, F., Prihanto, P.H., \& Amzar, Y.V. (2016). Analisis Pengaruh Belanja Modal terhadap Indeks Pembangunan Manusia di Provinsi Jambi. E-Jurnal Ekonomi Sumberdaya dan Lingkungan, 5(2), 1-15.

Badan Perencanaan Pembangunan Daerah. (2017). Tahun 2017, Belanja Badung Nyaris Tembus Rp 5 Triliun. Diunduh dari Bappeda Badung website http://bappeda.badungkab.go.id/informasi/informasi-nasional/tahun-2017belanja-badung-nyaris-tembus-rp-5-triliun 
Ida Ayu Tari Purnama Sasti dan Made Yenni Latrini. Pengaruh...

Badan Pusat Statistik. (2017). Indeks Pembangunan Manusia 2016. Agustus. BPS. Jakarta.

Badan Pusat Statistik. (2018). Indeks Pembangunan Manusia (IPM) 2017. Agustus. BPS. Jakarta.

Badan Pusat Statistik. (2018). Berita Resmi Statistik Indeks Pembangunan Manusia (IPM) Bali Tahun 2017. April. BPS Bali. Denpasar.

Connolly, A. T., Leoz, C. M. De, Gorospe, M., \& Sebastian, M. (2014). Determinants Of Having A High Human Development Index: A qualitative analysis on human development of countries all over the world, 1-29.

Deswantoro, D. B, Ismail, A., \& Hendarmin (2017). Pengaruh Belanja Daerah Berdasarkan Klasifikasi Ekonomi terhadap Pertumbuhan Ekonomi dan Kesejahteraan Masyarakat di Kabupaten/Kota Provinsi Kalimantan Barat Tahun 2010 - 2015. Jurnal Ekonomi Bisnis dan Kewirausahaan, 6(3), 187210 .

Dewi, I. G. A. A., \& Supadmi, N. L. (2016). Pengaruh Alokasi Belanja Rutin dan Belanja Modal pada Indeks Pembangunan Manusia. E-Jurnal Akuntansi Universitas Udayana, 14(1), 695-722.

Edeme, R. K. (2014). Analyzing the Effects of Sectoral Public Spending On Human Development in Nigeria: Evidence from Panel Data. IOSR Journal of Humanities and Social Science (IOSR-JHSS), 19(9), 1-13.

Ehimare, O.A, Barr. E.I.O, Joshua O. \& Uchechukwu E.O. (2014). The Nigerian Government Expenditure on Human Capital Development: an Efficiency Analysis. European Journal of Business and Social Sciences, 3(7) , 1-13. http://www.ejbss.com/recent.aspx-/

Fiddin, E., Pardamean, J. G. R., \& Geniusa, A., (2018). The Impact of Fiscal Decentralization on Economic Variables: Evidence From Indonesia's Provinces. Simposium Nasional Keuangan Negara, 1287-1306.

Ghozali, Imam. (2018). Aplikasi Analisis Multivariate dengan Program IBM SPSS 25. Semarang: Universitas Diponegoro.

Gogoi, Anuradha. (2017). A Study on Impact of Fiscal Decentralization on Human Development in India and an Insight into the Scenario of Fiscal Decentralization in Assam Compared to India. International Journal of Interdisciplinary and Multidisciplanary Studies, 4(3), 524-535. 
Hayek, F. A. (1945). The Use of Knowledge in Society. American Economic Review, 35(4), 519-530. https://doi.org/10.1257/aer.98.5.i

Hukom, A. (2015). Effect Of Capital Expenditures, Economic Growth And Poverty On Human Development In Central Kalimantan. IOSR Journal of Economics and Finance Ver. IV, 6(6), 2321-5933. https://doi.org/10.9790/ 5933-06641927

Ishak, J.F. (2016). Pengaruh Pendapatan Asli Daerah dan Belanja Modal Terhadap Indeks Pembangunan Manusia. Semnas Fekon, 565-569.

Jensen, M. C., \& Meckling, W. H. (1976). Theory of the firm: Managerial Behavior, Agency Costs And Ownership Structure. Journal of Financial Economics, 3(4), 305-360. https://doi.org/10.1016/0304-405X(76)90026-X

Jubery, Marwan, Moeljadi, Ananda C.F. \& Djazuli, AL. (2017). The Perspective of The Agency Theory in Budget Preparation of Local Government and its Implementation on Budget Performance and Financial Decentralization to Realize Performance of Local Government of Regencies and Cities in Banten Province. Russian Journal of Agricultural and Socio-Economic Sciences, 62(2), 42-54. https://doi.org/10.18551/rjoas.2017-02.06

Jumadi, Pudjiharjo, M., Maski, G., \& Khusaini, M. (2013). The Impact of Fiscal Secentralization on Local Economic Development in East Java. IOSR Journal Of Humanities And Social Science (IOSR-JHSS), 13(1), 1-7. https://doi.org/10.4335/15.3.685-703(2017)

Kresnandra, A.A.N.A. (2017). Pengaruh Desentralisasi Fiskal terhadap Pertumbuhan Ekonomi Daerah dengan Dana Perimbangan dan Investasi Swasta Sebagai Variabel Pemoderasi. Jurnal Bisnis dan Manajemen, 3(2), 44-63.

Mardiasmo. (2018). Akuntansi Sektor Publik (Edisi Terbaru), Yogyakarta: ANDI.

Mittal, P. (2016). Social Sector Expenditure and Human Development of Indian States. Expenditure. MPRA Paper No. 75804.

Musgrave, Richard. (1959). Theory of Public of Finance: A Study in Public Economy. New York: McGraw.

Ndakularak, E., Setiawina, N. D., \& Djayastra, I Ketut. (2014). Analisis FaktorFaktor yang Mempengaruhi Kesejahteraan Masyarakat Kabupaten/Kota di Provinsi Bali. E-Jurnal Ekonomi dan Bisnis Universitas Udayana, 3(3), 140153. 
Ida Ayu Tari Purnama Sasti dan Made Yenni Latrini. Pengaruh...

Oates, W.E. (1999). An Essay on Fiscal Federalism. Journal of Economic Literature, 37(3), 1120-1149.

Pahlevi, M. (2017). Impact of Governance and Government Expenditure on Human Development in Indonesia. Paper of International Institute of Social Studies, 1-54.

Pemerintah Kabupaten Jembrana. (2016). Membangun Jembrana dari Desa dan Kelurahan. Diunduh dari Pemerintah Kabupaten jembrana website: https://jembranakab.go.id./index.php?module=pendidikan

Peraturan Menteri Dalam Negeri Nomor 13 Tahun 2006 Tentang Pedoman Pengelolaan Keuangan Daerah. 15 Mei 2006. Jakarta.

Peraturan Pemerintah Nomor 71 Tahun 2010 tentang Standar Akuntansi Pemerintahan (SAP). 22 Oktober 2010. Lembaran Negara Republik Indonesia Tahun 2010 Nomor 123. Jakarta.

Peraturan Presiden Republik Indonesia Nomor 5 Tahun 2010 tentang Rencana Pembangunan Jangka Menengah Nasional Tahun 2010-2014. Jakarta.

Pradana, M. (2018). Alokasi Belanja Pemerintah dan Indeks Pembangunan Manusia di Indonesia. E-Journal Unitomo, 2(1), 1-15. https://doi.org/http:// dx.doi.org/10.25139/dev.v2i1.960

Pramartha, I. M. A., \& Dwirandra, A. A. N. B. (2018). Pengaruh Desentralisasi Fiskal, Belanja Modal, dan Investasi Swasta terhadap Indeks Pembangunan Manusia. E-Jurnal Akuntansi, 22(3), 2458-2482. https://doi.org/10.24843/ EJA.2018.v22.103.p30

Prasetyo, A. D., \& Zuhdi, U. (2013). The Government Expenditure Efficiency towards the Human Development. Procedia Economics and Finance, 5, 615622. https://doi.org/10.1016/S2212-5671(13)00072-5

Priambodo, A. (2015). Analisis Pengaruh Belanja Pemerintah Daerah Terhadap Indeks Pembangunan Manusia. Jurnal Ilmiah Fakultas Ekonomi dan Bisnis Universitas Brawijaya Malang, 3(2), 21-.43. https://doi.org/10.5281/zenodo. 824398

Prihastuti, A. H. (2018). Pengaruh Alokasi Belanja Modal dan Pertumbuhan Ekonomi Terhadap Indeks Pembangunan Manusia di Kabupaten/Kota Riau. Menara Ekonomi, 6(1), 1-8.

Sari, A. K., Saputra, H., \& Siahaan, A. P. U. (2017). Effect of Fiscal Independence and Local Revenue Against Human Development Index. International Journal of Business and Management Invention, 6(7), 62-65. 
Sari, I. A. C. Y., \& Supadmi, N. L. (2016). Pengaruh Pendapatan Asli Daerah dan Belanja Modal Pada Peningkatan Indeks Pembangunan Manusia. E-Jurnal Akuntansi Universitas Udayana, 15(3), 2409-2438.

Sasana, H. (2012). Pengaruh Belanja Pemerintah Daerah dan Pendapatan per Kapita terhadap Indeks Pembangunan Manusia. Media Ekonomi dan Manajemen, 25(1), 1-12.

Slavinskaite, N. (2017). Fiscal decentralization dnd Economic Growth In Selected European Countries. Journal of Business Economics and Management, 18(4), 745-757. https://doi.org/10.3846/16111699.2017.1292312

Soejoto, A., Subroto, W. T., \& Suyanto. (2015). Fiscal Decentralization Policy in Promoting Indonesia Human Development. International Journal of Economics and Financial Issues, 5(3), 763-771.

Sugiyono. (2017). Metode Penelitian Bisnis. Bandung: CV Alfabeta.

Syam, A. Y., Rizani, F., \& Maladi, M. (2018). The Effect of Local Original Revenues, Special Allocation Funds, General Allocation Funds on The Human Development Quality and The Mediating Role Of Capital Expenditure in Regency and Cities in South Kalimantan Province Indonesia. Conference of Engineering, Science and Humanities, 899-901.

Umiyati, E., Amril, Zulfanetti. (2017). Pengaruh Belanja Modal, Pertumbuhan Ekonomi dan Jumlah Penduduk Miskin Terhadap Indeks Pembangunan Manusia di Kabupaten/Kota Provinsi Jambi. Jurnal Sains Sosiohumaniora, 29-37.

Undang-Undang Republik Indonesia Nomor 32 Tahun 2004 Tentang Pemerintahan Daerah. 15 Oktober 2004. Lembaran Negara Republik Indonesia Tahun 2004 Nomor 125. Jakarta.

Undang-Undang Republik Indonesia Nomor 36 Tahun 2009 Tentang Kesehatan. 13 Oktober 2009. Lembaran Negara Republik Indonesia Tahun 2009 Nomor 144. Jakarta.

Undang-Undang Republik Indonesia Nomor 15 Tahun 2013 Tentang Perubahan Atas Undang-Uundang Nomor 19 Tahun 2012 tentang Anggaran Pendapatan dan Belanja Negara Tahun Anggaran 2013. 18 Juni 2013. Lembaran Negara Republik Indonesia Tahun 2013 Nomor 108. Jakarta.

Undang-Undang Republik Indonesia Nomor 23 Tahun 2014 tentang Pemerintahan Daerah. 2 Oktober 2014. Lembaran Negara Republik Indonesia Tahun 2014 Nomor 244. Jakarta. 
Ida Ayu Tari Purnama Sasti dan Made Yenni Latrini. Pengaruh...

UNDP. (1990). Human Development Report 1990. New York: Oxford University Press.

UNDP. (2010). Human Development Report 2010. New York: United Nations Development Programme.

Yusuf, N. A. F. (2014). Analisis Pengaruh Desentralisasi Fiskal Terhadap Indeks Pembangunan Manusia Di Kabupaten/Kota Eks Karesidenan Surakarta, EJournal UNDIP, 5(2), 12-21.

Zahari, M. MS. (2017). The Effect of Government Expenditures in Education and Health against Human Development Index in Jambi Province. The International Journal of Social Sciences and Humanities Invention, 4(8), 3823-3829. https://doi.org/10.18535/ijsshi/v4i8.21

Zebua, W. F. \& Adib, N. (2014). Pengaruh Alokasi Belanja Modal, Belanja Barang dan Jasa, Belanja Hibah, dan Belanja Bantuan Sosial terhadap Kualitas Pembangunan Manusia (Studi pada Kabupaten dan Kota di Wilayah Provinsi Jawa Barat Tahun 2011-2013). Jurnal Ilmiah Mahasiswa FEB, 3(1), $1-18$. 